\title{
Penerapan Algoritma Apriori Terhadap Data Penjualan di Toko Gudang BM
}

\author{
Aditya $^{1}$, Fitri Marisa ${ }^{2}$, Dwi Purnomo ${ }^{3}$
}

\begin{abstract}
Ease to sell a product on the market using the internet makes many traders emerging. Limited capital constraint most of the new traders. Application of apriori algorithm to look for products that are sold in the market can solve the problem of new traders. Apriori algorithm is one branch of data mining, which is used to search for informations from a data set. In this study, the results of the apriori algorithm can be used to be considered in making marketing strategic, sales optimization, as well as a material consideration for restocking.

Intisari- Kemudahan untuk menjual suatu produk di pasaran menggunakan media internet membuat banyaknya pedagang pedagang baru bermunculan. Keterbatasan modal menjadi kendala sebagian besar pedagang baru tersebut. Penerapan algoritma apriori untuk mencari produk yang laku di pasaran dapat mengatasi masalah pedagang baru tersebut. Algoritma apriori merupakan salah satu cabang dari data mining, yang berfungsi untuk mencari informasi - informasi dari sebuah kumpulan data. Dalam penelitian ini, hasil algoritma apriori dapat digunakan untuk menjadi bahan pertimbangan dalam membuat strategi pemasaran, pengoptimalan penjualan, serta sebagai bahan pertimbangan untuk melakukan penyetokan ulang.
\end{abstract}

Kata Kunci-data mining, e-commerce, algoritma apriori.

\section{PENDAHULUAN}

\subsection{LATAR BELAKANG}

Penjualan online kini lebih diminati pembeli karena pembeli tidak perlu repot-repot untuk datang ke toko dan membeli sebuah produk. Pembeli cukup menggunakan internet dan dapat langsung melihat-lihat maupun mem-beli sebuah produk. Ini yang membuat persaingan penjual semakin ketat.

Seperti masalah yang di alami oleh toko GudangBM. Meskipun toko ini sudah berjalan cukup lama, tetapi sering mengalami masalah barang ti-dak laku.

Untuk mengatasi masalah ini, maka timbul upaya untuk memilih ba-rang yang tepat dan cepat laku di pa-saran. Hal ini bertujuan untuk mem-buat usaha yang dirintis terus berjalan. Data mining sangat cocok untuk kasus seperti ini.

Berdasarkan latar belakang di-atas, maka penulis menguraikan tuju-an dan manfaat yang akan di bahas, yaitu untuk mengembangkan sistem infor-masi $e$-commerce di toko Gudang BM dengan menggunakan konsep data mining (pendekatan algoritma apriori) se-hingga dapat menganalisis perilaku pembeli.

\footnotetext{
${ }^{1}$ Mahasiswa, Teknik Informatika Universitas Widyagama Malang (email: jointecs.uwg@gmail.com)

2,3 Dosen Pembimbing I, II, Jurusan Teknik Informatika Universitas Widyagama, Jln. Borobudur No. 35 Malang 65128 INDONESIA (telp: 0341-492282, 491648; fax: 0341-496919;

e-mail:fitrimarisa@widyagama.net, purnomo_it@yahoo.com)
}

\section{TINJAUAN PUSTAKA}

\subsection{Data Mining}

Menurut Turban (2005) dalam Ridwan (2013), data mining adalah proses yang menggunakan teknik sta-tistik, matematika, kecerdasan buatan, dan machine learning untuk meng-ekstraksi dan mengidentifikasi infor-masi yang bermanfaat dan pengetahu-an yang terkait dari berbagai database besar.

Selain itu, data mining adalah su-atu teknik menggali informasi berhar-ga yang terpendam atau tersembunyi pada suatu koleksi data (database) yang sangat besar sehingga ditemukan suatu pola yang menarik yang sebe-lumnya tidak diketahui. (Calam, 2011).

\subsubsection{TAHAPAN DATA MINING}

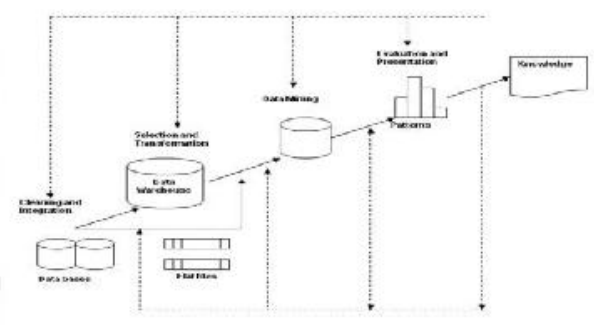

Gambar 2.1 : Tahapan data mining

a) Data Cleaning (untuk menghilang-kan noise data yang tidak konsisten) Data Integration (dimana sumber da-ta yang terpecah dapat disatukan.

b) Data selection (di mana data yang relevan dengan tugas analisis dikem-balikan ke dalam database).

c) Data transformation (di mana data berubah atau bersatu menjadi bentuk yang tepat untuk menambang de-ngan ringkasan performa atau opera-si agresi).

d) Data mining (proses esensial di mana metode yang intelijen diguna-kan untuk mengekstrak pola data).

e) Pattern evolution (untuk mengiden-tifikasi pola yang benarbenar mena-rik yang mewakili pengetahuan ber-dasarkan atas beberapa tindakan yang menarik).

f) Knowledge presentation (di mana gambaran teknik visualisasi dan pe-ngetahuan digunakan untuk membe-rikan pengetahuan yang telah ditam-bang kepada user).

\subsection{Web Mining}

Web mining merupakan salah satu teknik penggalian data yang menggunakan objek website. Hampir sama dengan data mining, hanya saja perbedaannya berupa media / objek yang akan digali.

\subsubsection{Web Struktur Mining}

Web struktur mining akan lebih fokus pada analisis graf yang terbentuk dari struktur tautan dalam satu lingku-ngan atau batasan satu atau beberapa web. Setelah graf jejaring web terben-tuk, maka kita dapat menganalisis graf tersebut. Misalnya dengan mengguna-kan PageRank, kita dapat 
mengetahui web mana yang lebih dipercaya. Algo-ritma HITS juga dapat digunakan un-tuk mengetahui web mana yang menja-di sumber utama dalam satu topik ter-tentu. Penerapan pencocokan graf juga dapat diterapkan untuk melihat kemiripan struktur antar web. Bahkan kita dapat menggunakan metode Social Network Analysis untuk menemukan centrality misalnya diantara kerumu-nan jejaring web. Dengan kata lain al-goritma graf dapat digunakan untuk analisis jejaring web tersebut.

\subsubsection{Web Konten Mining}

Web konten mining adalah tahapan dalam preprocessingnya akan menerapkan seperti yang dilakukan dalam text mining pada umumnya. Ha-nya saja yang perlu untuk ditekankan di sini adalah harus dapat membuang semua elemen yang dirasa tidak pen-ting terhadap content (misalnya ele-men format bold, italic, dsb.). Dalam pembersihan ini, elemenelemen yang dapat memberi arti lebih terhadap isi web harus juga diperhatikan, seperti e-lemen meta, ataupun jika dalam hala-man web mengandung metadata atau-pun microdata dan microformat. Se-telah bersih dan dilakukan tokenisasi ataupun parsing, biasanya akan digu-nakan metode information retrieval ataupun data mining seperti clustering dan klasifikasi. Semua metode tersebut digunakan untuk dapat menemukan pola informasi yang tidak langsung ter-lihat jika hanya menggunakan proses statistik dasar.

\subsubsection{Web Usage Mining}

Web usage mining akan fokus menganalisis transaksi yang diproses dari data log yang dihasilkan web ser-ver. Analisis transaksi misalnya asosi-asi dan analisis pola urutan akses web. Namun pemanfaatan hanya dari log server tidaklah cukup dapat dihandal-kan untuk digunakan dalam hak anali-sis transaksi. Salah satu penyebabnya adalah adanya proxy server dan caching pada web browser yang menye-babkan catatan log server menjadi ti-dak lengkap. Dalam hal ini perlu diper-timbangkan pemanfaatan cookie dan klik dari user berdasar sesi dalam web browser.

\subsection{Aturan Asosiasi}

Aturan asosiasi merupakan sa-lah satu metode yang bertujuan menca-ri pola yang sering muncul di antara banyak transaksi, dimana setiap tran-saksi terdiri dari beberapa item, se-hingga metode ini akan mendukung sistem rekomendasi penjualan hand-phone pada toko GudangBM yang da-pat memudahkan calon pembeli dalam pemilihan barang melalui penemuan pola antar item dalam transaksi - tran-saksi yang terjadi di toko GudangBM.

Aturan asosiasi ini nantinya akan menghasilkan aturan yang me-nentukan seberapa besar hubungan antar X dan Y, dan diperlukan dua ukuran untuk aturan ini, yakni support dan confidence.

Support adalah nilai penunjang atau presentase kombinasi sebuah item dalam database. Sedangkan confidence adalah nilai kepastian yaitu kuatnya hubungan antar item dalam sebuah apriori. Confidence bisa dicari setelah pola frekuensi munculnya sebuah item ditemukan.

\subsection{Algoritma Apriori}

Algoritma apriori adalah algoritma dasar yang diusulkan oleh Agrawal dan Srikant pada tahun 1994 untuk penentuan frequent itemsets un-tuk aturan asosiasi Boolean. (Sensuse, 012). Algoritma ini mengontrol ber-kembangnya kandidat itemset dari ha-sil frequent itemsets dengan support-based pruning untuk menghilangkan itemset yang tidak menarik dengan me-netapkan minsup. (Wandi, 2012).

Algoritma apriori juga dapat didefinisikan sebagai suatu proses un-tuk menemukan semua aturan apriori yang memenuhi syarat minimum untuk support dan syarat minimum untuk confidence. (Syaifullah, 2010).

Selain itu, algoritma Teknik da-ta mining dengan algoritma apriori da-pat diimplementasikan pada sistem penjualan (Syaifullah, 2010). Adapun software yang dibuat menggunakan algoritma apriori ini dapat mengetahui produk mana yang sering di beli oleh konsumen sehingga nantinya dapat mengetahui pola konsumsi konsumen. (Heru Dewantara, 2013).

\section{ANALISIS PERANCANG}

\subsection{Algoritma Apriori Menggunakan Aturan Asosiasi}

Pada tahap ini bertujuan untuk mencari kombinasi dari item - item dengan pola frekuensi dari hasil tran-saksi pada toko GudangBM.

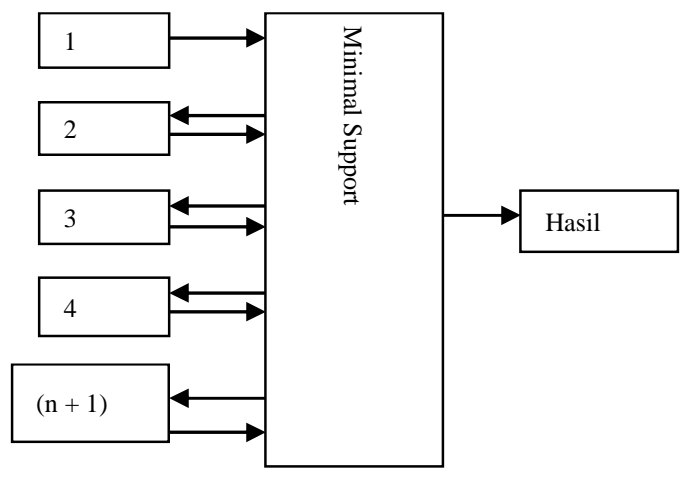

Gambar 3.1 : Bagan alur apriori

Dari bagan alur diatas, algoritma apriori akan terus dilakukan jika kon-disi data masih memungkinkan untuk itemset berikutnya. Jika tidak me-mungkinkan maka langsung menjadi hasil.

Berikut adalah rekapan transaksi 2 bulan sebelumnya :

Tabel 3.1 : Data Transaksi

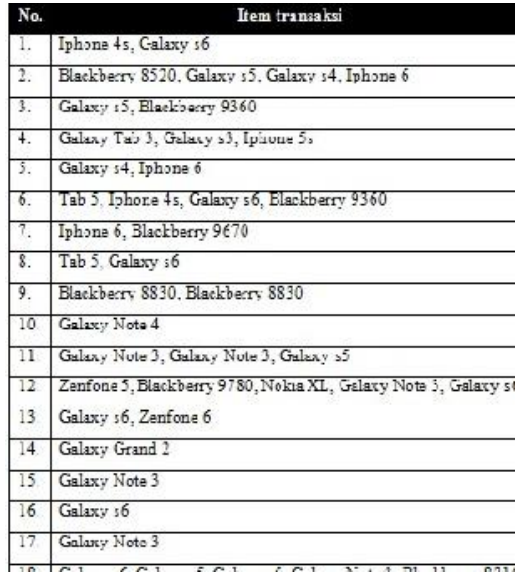

Tabel 3.2 : Tabel transaksi per item (1-itemset) 


\begin{tabular}{|c|c|}
\hline ITEM TRANSAKSI & BANYAKNYA ITEM \\
\hline Galaxy 56 & 9 \\
\hline Galaxy 55 & 9 \\
\hline Galaxy Note 3 & 8 \\
\hline Iphone 6 & 7 \\
\hline
\end{tabular}

Pada tabel 3.2 total maksimal suatu transaksi yaitu 9 dan yang terendah adalah 1. Jika ditampilkan pada sebuah tabel akan menjadi sebagai berikut.

Tabel 3.3 : Tabel transaksi per item (2-itemset)

\begin{tabular}{|l|c|l|c|}
\hline \multicolumn{2}{|l|}{ Item transaksi } & $\begin{array}{c}\text { Banyaknya } \\
\text { transaksi }\end{array}$ & \multicolumn{2}{c|}{ Item transaksi } & $\begin{array}{c}\text { Banyaknya } \\
\text { transaksi }\end{array}$ \\
\hline Iphone 45 & 3 & Galaxy Note 3 & 8 \\
\hline Galaxy 56 & 9 & Zenfone 5 & 2 \\
\hline Blackberry 8520 & 1 & Blackberry 9780 & 1 \\
\hline Galaxy s5 & 9 & Zenfone 6 & 1 \\
\hline Galaxy s4 & 4 & Galaxy Grand 2 & 1 \\
\hline Iphone 6 & 7 & Blackberry 8310 & 1 \\
\hline Blackberry 9360 & 2 & Redmi 2s & 2 \\
\hline Galaxy Tab 3 & 1 & Redmi 15 & 1 \\
\hline Galaxy 53 & 1 & Blackberry 9350 & 1 \\
\hline Iphone 55 & 3 & Blackberry z30 & 1
\end{tabular}

Tabel 3.4 : Tabel transaksi per item (3-itemset)

\begin{tabular}{|l|c|}
\hline \multicolumn{1}{|c|}{ ITEM TRANSAKSI } & BANYAKNYA ITEM \\
\hline Galaxy 56, Galaxy 55 & 2 \\
\hline Galaxy 56, Galaxy Note 3 & 3 \\
\hline Galaxy 56, Iphone 6 & 0 \\
\hline Galaxy 55, Galaxy Note 3 & 2 \\
\hline Galaxy 55, Iphone 6 & 2 \\
\hline Galaxy Note 3, Iphone 6 & 0 \\
\hline
\end{tabular}

Tabel 3.5 : Tabel transaksi per item (4-itemset)

\begin{tabular}{|l|c|}
\hline ITEM TRANSAKSI & BANYAKNYA ITEM \\
\hline Galaxy s6, Galaxy 55, Galaxy Note 3 & 1 \\
\hline Galaxy 56, Galaxy 55, Iphone 6 & 0 \\
\hline Galaxy 56, Galaxy Note 3, Iphone 6 & 0 \\
\hline Galaxy 55, Galaxy Note 3, Iphone 6 & 0 \\
\hline
\end{tabular}

Setelah mendapatkan 2-itemset tahap selanjutnya adalah menggabung-kan item - item 2-itemset satu sama lain. Hasilnya dapat kita lihat pada ta-bel di bawah ini.

Dapat dilihat pada tabel di atas (tabel 3.4), masih terdapat transaksi yang nilainya 0 atau tidak memiliki ri-wayat transaksi bersamaan. Oleh kare-na itu kita akan membuangnya kemudian mengkombinasikan lagi transaksi - transaksi per item tersebut.

Setelah memilih item - item untuk peluang support, selanjutnya kita gunakan untuk mencari peluang confidence.
Tabel 3.6 : Tabel Confidence per item

\begin{tabular}{|l|l|l|}
\hline \multicolumn{2}{|c|}{ ITEM TRANSAKSI } & $22,2 \%$ \\
\hline $\begin{array}{l}\text { Jika membeli Galaxy 56, maka akan } \\
\text { membeli Galaxy s5 }\end{array}$ & $2 / 9$ & \\
\hline $\begin{array}{l}\text { Jika membeli Galaxy s6, maka akan } \\
\text { membeli Galaxy Note 3 }\end{array}$ & $3 / 9$ & $33,3 \%$ \\
\hline $\begin{array}{l}\text { Jika membeli Galaxy 55, maka akan } \\
\text { membeli Galaxy s6 }\end{array}$ & $3 / 9$ & $33,3 \%$ \\
\hline $\begin{array}{l}\text { Jika membeli Galaxy s5, maka akan } \\
\text { membeli Galaxy Note 3 }\end{array}$ & $2 / 9$ & $22,2 \%$ \\
\hline $\begin{array}{l}\text { Jika membeli Galaxy Note 3, maka } \\
\text { akan membeli Galaxy s6 }\end{array}$ & $3 / 8$ & $37,5 \%$ \\
\hline $\begin{array}{l}\text { Jika membeli Galaxy Note 3, maka } \\
\text { akan membeli Galaxy s5 }\end{array}$ & $2 / 8$ & $25,5 \%$ \\
\hline
\end{tabular}

\subsubsection{Flowchart}

Tabel 3.7 : Tabel diagram alir sistem sebelum dan rekomendasi sistem tambahan pada toko GudangBM

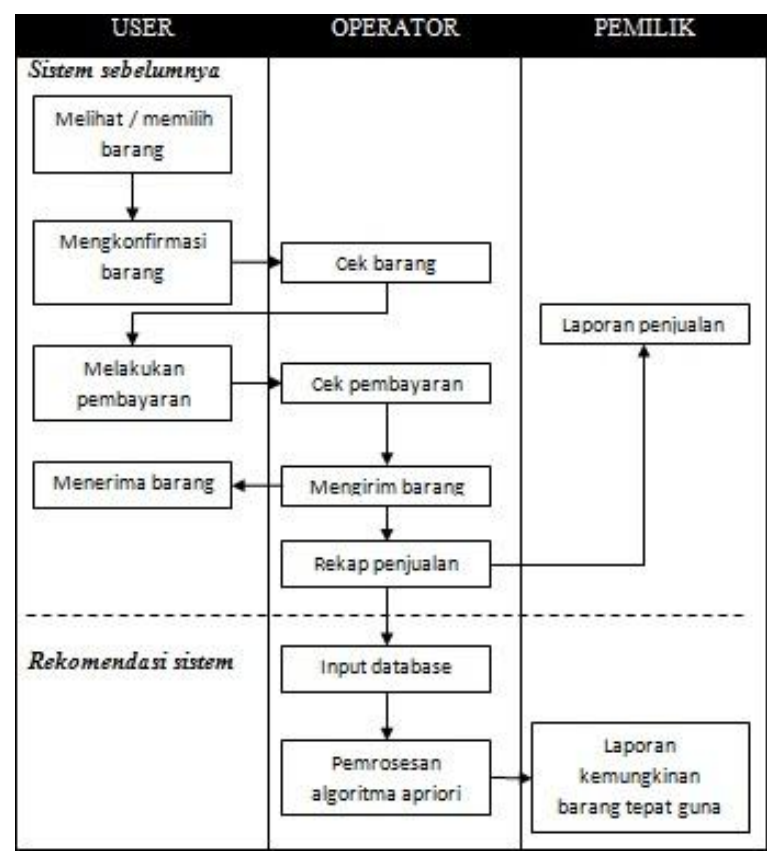

\subsubsection{Data Flow Diagram (DFD)}

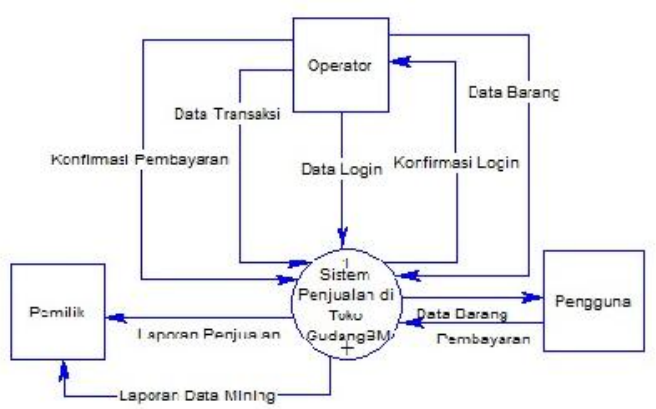

Gambar 3.2 : Diagram Konteks 


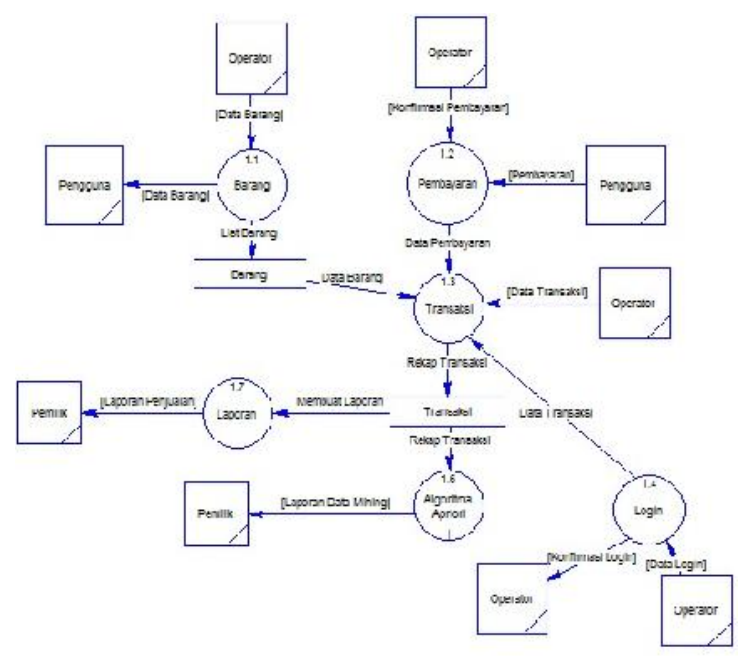

Gambar 3.3 : DFD level 0

\subsubsection{ERD}

Berikut adalah tabel relasi serta gambar relasinya.

Gambar 3.5 : Tabel Relasi

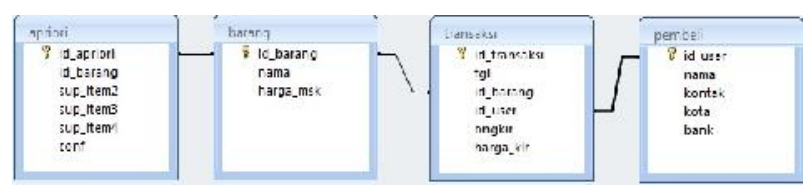

Gambar 3.6 : ERD

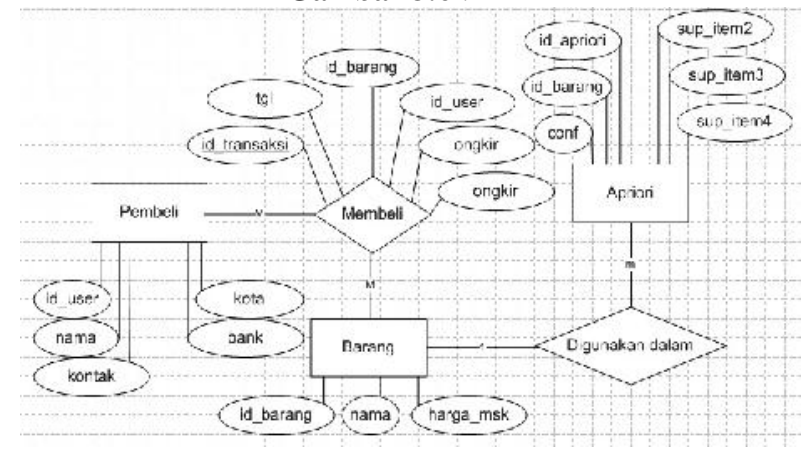

IV. IMPLEMENTASI

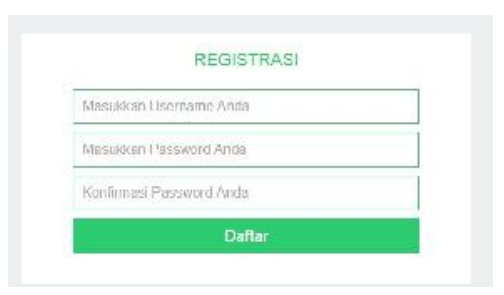

Gambar 4.1 : Halaman pendaftaran

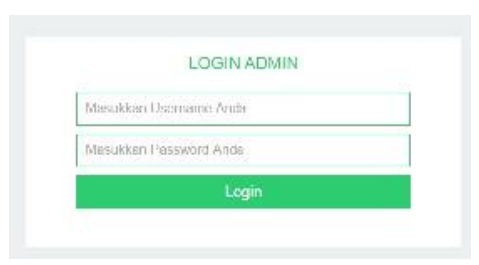

Gambar 4.2 : Halaman login
Input Data

\begin{tabular}{|l|l|l|}
\hline Input Data & Analisis Dala & Logout \\
\hline
\end{tabular}

\begin{tabular}{|l|c|c|c|c|c|}
\hline No. & Tanggal & Barang & User & Ongkt & Harga \\
\hline 1 & $7110 / 2015$, & RPRiM8500 & 1 Husin & & \\
\hline & & & Tambah Kolon & Simpan \\
\hline
\end{tabular}

Gambar 4.3 : Halaman input data

\begin{tabular}{|c|c|c|}
\hline \multicolumn{3}{|r|}{ Analisis Data } \\
\hline Input Data & Analisis Data & Logout \\
\hline \multicolumn{3}{|c|}{ Dut: Transaks 2 Bular Telakhii } \\
\hline \multicolumn{2}{|c|}{ Tanggal Transaksi } & Item Traneakai \\
\hline & \multirow[t]{2}{*}{ BEER.19520 } \\
\hline 2002015 & & \\
\hline \multicolumn{2}{|c|}{$35 \times 2015$} & БLLA96/O \\
\hline \multicolumn{2}{|c|}{ 1, 52012015} & IRRE $15: 2$ \\
\hline \multicolumn{2}{|c|}{ : } & 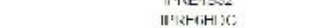 \\
\hline \multicolumn{2}{|c|}{$6=2015$} & Wh:3416 \\
\hline \multicolumn{2}{|c|}{ 7):2015 } & 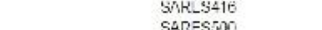 \\
\hline \multicolumn{2}{|c|}{ Хมวग11: } & \\
\hline \multicolumn{2}{|c|}{932015} & 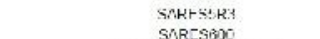 \\
\hline \multicolumn{2}{|c|}{1009015} & $S A R=S T S A R B=-A R 3$ \\
\hline \multicolumn{2}{|c|}{$x x^{2}=01015$} & SWARI IN1ES \\
\hline \multicolumn{2}{|c|}{328,2015} & SAR TAOB3 \\
\hline \multicolumn{2}{|c|}{ Gtoiontri } & ARFWPIIO SARRFTARS SARFTAR3 \\
\hline \multicolumn{3}{|c|}{ Tuled Tranisaksi Per llem } \\
\hline \multicolumn{2}{|c|}{ Hom Transaksi } & Total Transaksi \\
\hline \multicolumn{2}{|r|}{ DoCM05:0 } & 2 \\
\hline & RARMA3CE: & $i$ \\
\hline & LULLM:STO & 1 \\
\hline & IIRE-1S32 & 1 \\
\hline & IMRFIARC & 1 \\
\hline & SNOLLS 416 & 1 \\
\hline & SARESECO & 2 \\
\hline & SALIF SIllz 3 & 1 \\
\hline & SAHLSEOW & 1 \\
\hline & SARETAB 3 & 3 \\
\hline
\end{tabular}

Gambar 4.4 : Halaman analisis data

Di halaman ini terdapat 2 informasi penting yang dibutuhkan pemilik, yaitu informasi hasil proses algoritma apriori dan informasi barang tidak laku.

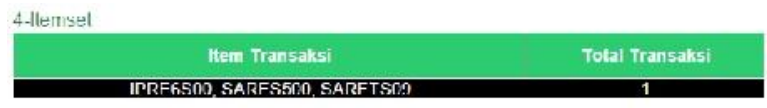

Gambar 4.5 : Hasil Algoritma Apriori

Buırng Trdek Luku ( Tulel Trunsaksi Kuın! Deri 20\% Duri Trunsuksi Muksimal )

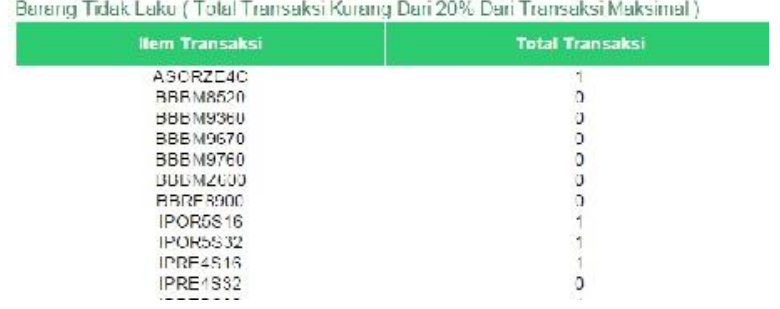

Gambar 4.6 : Informasi Barang Tidak Laku

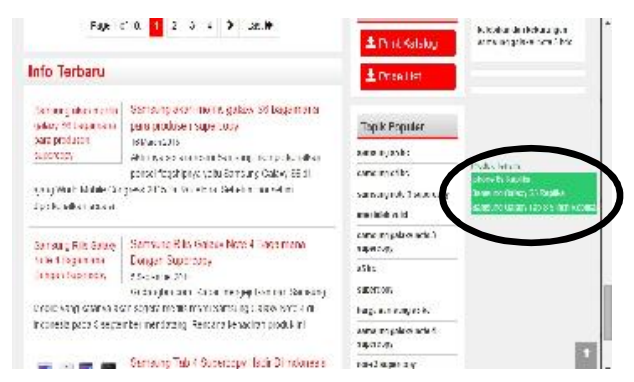

Gambar 4.7 : Halaman utama 
Berikut ini adalah gambar daerah lingkaran hitam tersebut.

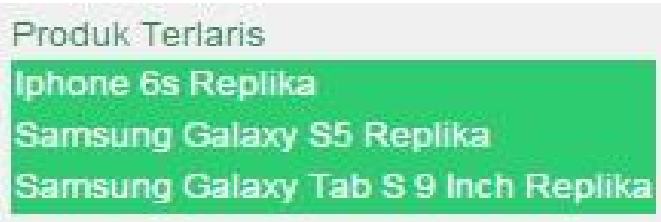

Gambar 4.8 : Hasil Algoritma Apriori di Halaman Utama

\section{PENUTUP}

Dari pokok pembahasan masalah yang telah dibahas sebelumnya, dapat kita ambil kesimpulan sebagai berikut :

a. Dengan adanya proses data mining terhadap penjualan produk handphone di toko GudangBM maka akan memudahkan dalam proses pemilihan stok.

b. Barang apa saja yang memiliki kemungkinan laku terjual pada bulan tersebut dan barang apa saja yang tidak laku atau kurang laku pada bulan tersebut (dengan data yang diproses 2 bulan terakhir).

c. Serta dapat memberikan rekomen-dasi untuk calon pembeli yang mengunjungi website dan akan membeli sebuah barang.

Sistem ini bisa dikembangkan menjadi lebih baik lagi dengan menambahkan beberapa hal berikut :

a. Pemilihan minsup yang bisa di atur oleh operator sesuai kebutuh-an.

b. Penambahan desain yang di terapkan di halaman utama agar lebih menarik untuk dilihat pengunjung.

c. Penerapan algoritma yang lebih mantap.

Penambahan gambar beserta link dalam setiap produk agar lebih memudahkan calon pembeli mela-kukan pencarian.

\section{REFERENSI}

[1] Afyenni, R. (2014, April 1). PERANCANGaN DATA FLOW DIAGRAM UNTUK SISTEM INFORMASI SEKOLAH (STUDI KASUS PADA SMA PEMBANGUNAN LABORATORIUM UNP). Jurnal TEKNOIF , 2, 35-39

[2] Aman Budi Manduro, S. M. (2011, Mei 26). Pengembangan Sistem Informasi Lapas Narkoba Untuk Menunjang Pengungkapan Kasus Narkoba di Lembaga Pemasyarakatan Pada Puslitbang dan Info Badan Narkotika Nasional. Jurnal Ilmiah Universitas Gunadarma , 6.

[3] Calam, D. W. (2011). PENERAPAN DATA MINING UNTUK MENGOLAH DATA PENEMPATAN BUKU DI PERPUSTAKAAN SMK TI PAB 7 LUBUK PAKAM DENGAN METODE ASSOCIATION RULE. Jurnal SAINTIKOM , 10 (2), 150.

[4] Dewi Rosmala, M. D. (2012). IMPLEMENTASI APLIKASI WEBSITE E-COMMERCE BATIK SUNDA DENGAN MENGGUNAKAN PROTOKOL SECURE SOCKET LAYER (SSL). Jurnal Informatika , 3 (3), 58-67.

[5] Fathansyah. 2010. BasisData. Jakarta : Elex Media Komputindo.

[6] Mujib Ridwan, H. S. (2013). Penerapan Data Mining Untuk Evaluasi Kinerja Akademik Mahasiswa Menggunakan Algoritma Naive Bayes Classifier. Jurnal EECCIS , 7 (1), 59-64.

[7] Nugroho Wandi, R. A. (2012). Pengembangan Sistem Rekomendasi Penelusuran Buku dengan Penggalian Association Rule Menggunakan Algoritma Apriori (Studi Kasus Badan Perpustakaan dan Kearsipan Provinsi Jawa Timur). Jurnal Teknik ITS , 1, A-445-A-449.

[8] Sensuse, G. G. (2012). PENERAPAN METODE DATA MINING MARKET BASKET ANALYSIS TERHADAP DATA PENJUALAN PRODUK BUKU DENGAN MENGGUNAKAN ALGORITMA APRIORI DAN FREQUENT PATTERN GROWTH (FP-GROWTH) : STUDI KASUS PERCETAKAN PT. GRAMEDIA. Jurnal TELEMATIKA MKOM , 4 (1), 118-132.
[9] Sulaiman, D. (2012, Maret 17). PHP \& MySQL. Retrieved Desember 14, 2014, from Arsip Teknik Informatika UMMI: http://www.ummi.ac.id/ti/detail_jurnal.php?page=ZGV0YWlsX2p1cm $5 \mathrm{hbHBocA}==\&$ no $=$ VGxSUIBRPT0 $=$

[10] Sutrisno, J. (2011). STRATEGI PENGEMBANGAN TEKNOLOGI E-COMMERCE DENGAN METODE SWOT : STUDI KASUS: PT. CHINGMIX BERHAN SEJAHTERA. Jurnal TELEMATIKA MKOM , 3 (2), 44-50.

[11] Syaifullah, M. A. (2010). IMPLEMENTASI DATA MINING ALGORITMA APRIORI PADA SISTEM PENJUALAN. STMIK AMIKOM YOGYAKARTA. Yogyakarta: Sekolah Tinggi Manajemen Informatika dan Komputer Amikom. 